\title{
Mapping Basic Needs Economic Development, Progress and Sustainable Development at the Iberoamerican Region
}

\author{
João Almeida Santos, Maria Cristina Sanches Amorim, \\ School of Management, Pontifical Catholic University of \\ Sao Paulo, Sao Paulo, Brazil \\ E-mail: rrofessoralmeida@ig.com.br, cris.amorim@pucsp.br,
}

\begin{abstract}
This article studies the performance of 132 countries ranked in 3 Regions Iberoamerican Region( AIBER ), AVECO Region (more developed countries) and OTHERS Region (less developed countries ) analyzing indicators related to Basic Needs: Food, Water, Electricity, Energy. Basic Needs Conditions are closely interconnected, reflect development conditions, and may be monitored and analyzed through a set of worldwide country indicators; so they may help for a Regional Diagnosis as well as for Developing Strategic Planning. As a matter of fact the study suggests that even countries with low GDP may still improve food quality through increased investment in food production; so that appropriate public policies may find ways that lead to improve quality of life with food, water and energy where is more needed at The Iberoamerican Region. All this may Foster Sustainable Development locally and Globally speaking.
\end{abstract}

Key words: Food; Water; Electricity; HDI; Iberoamerican region 


\section{INTRODUCTION}

The increase of the population living in big cities show that problems with the lack of clean water and food are linked to other problems such as lack of economic growth, employment, income distribution and sustainable development.

Food, water and energy are vital elements for livelihood at any place around the world. But still today one in eight people in the world were estimated to be suffering from chronic hunger. Moreover according to the UN-Water one in 9 people do not have access to safe and clean drinking water and almost 2.5 billion do not have access to adequate sanitation.

The countries of Ibero-America were colonized and have gone through many times of political instability and therefore not were able to form a satisfactory structure for the population. Today it is still very common to find people living in different countries of the region without clean water, sanitation, food in quantity and quality to have a happy life.

The difference inside the Iberoamerican Region is great when we consider the indicators food, clean water, economic growth and sustainable development. For example, Chile has economic development indicators better than Bolivia, Ecuador and Brazil in many ways. The size of the country and the internal cultural diversity are factors that affect the overall framework for evaluating economic development. In this sense, Brazil has a disadvantage because of the size of its territory, the cultural difference between people from one state to another, use of natural resources and this is seen in the HDI indicator - Human Development Index.

Only the territory size does not justify the low score of the indicators and the actual effects on the life of a population. When we approach the food issue, we must consider what other resources are necessary and must be used to produce food. For example: electric power, water, labor, machinery and equipment to prepare the land for planting and harvesting, transport and storage. Food, water, energy electricity and GDP - Gross Domestic Product - are closely interconnected regarding development conditions; and may be analyzed and monitored through a set of available indicators, as may be shown through this paper. The use of natural resources and the creation of means for production of more food should be a priority for a good policy of government. Investing in education and manpower training to work in the field, learning how to use the agricultural equipment to better enjoy their potential are some measures that improve the result of food production.

Hélder Muteia representing the United Nations Food and Agriculture Organization (FAO) in Brazil states that in a global economic crisis situation, the demand for food of a population expected to reach 9 billion by 2050, imposes global leadership challenge to increase agricultural production in a sustainable way. "It will not be easy. To answer this demand, global food production must grow by about $70 \%$. "

The public policies must meet the growing demand for food and investments in other sectors that are the basis for agricultural production. In this regard, governments should have policies of economic growth with investments in various areas so that people can have more food, treated water, electric power and other benefits.

The paper shows that basic needs all over the region have being improved along the time, but that there is still a long way to go and there more and more a greater need to care not only about quantity but also about quality of products and processes if we think on Regional Sustainable Development. 


\section{THE IBEROAMERICA REGION}

In this study, the IberoAmerican Region ( 21 countries ) includes Portugal and Spain that left strong socio-cultural roots in the Latinamerican Region.

There are many differences between the region's countries as territory size, number of inhabitants, the availability of natural resources and wealth. Thus, we can cite the case of Chile which has a copper reserve that is a natural wealth and the basis of its economy, Venezuela has the oil as the basis of their wealth and Brazil that have natural wealth with availability of sun and water for agriculture but with problems because of the size of its territory which creates logistical problems for the transport of food and its storage.

More recently the United States and Cuba are getting closer so that should increase investment in various sectors because of the economic gap with the end of the economic embargo that was imposed to Cuba in the past fifty years.

\section{Water and food production}

The world agricultural production has tripled in the last 50 years, mainly due to higher productivity per unit of land and intensification of crops. The overall supply of food per capita increased from 2,200 kcal / day at the beginning of the 1960 to more than $2800 \mathrm{kcal} /$ day in 2009. In $3370 \mathrm{kcal} /$ person / day, Europe currently has the highest rate per capita average supply food. The cereal production occupies more than half of the cultivated area worldwide and is the most important source of food for human consumption. Of the 2.3 tons of cereals each year, 1 billion is intended for human consumption, 750 million tons are used for animal feed and 500 million tons are either processed by industry, used in food or wasted (FAO, 2013).

Although water is an easy product to be obtained in some places on earth, the most populated cities it has been more difficult to find. This fact is because there was a population growth unchecked in these cities and water resources was difficult to be treated to be redistributed again, because there was no natural water easy to be obtained and abundant. It is necessary for all human beings, plants and animals. For washing and cleaning in general, to cooking, maintaining the hydrated plants and eliminating thirsty animals.

Many regions in the world are increasingly facing water scarcity which constraints agricultural production and limits the incomes and livelihoods of many residents in rural and urban areas.

Both in cities and rural areas is necessary to invest in water treatment and sanitation facilities for obtaining pure and natural water is increasingly difficult. Therefore, it is necessary to invest in water treatment for it to be used several times by humans. Investments in drinking water supplies, water quality, sanitation and health care to focus on, especially women and children are essential to ensure urban and rural residents can fully use food and nutrition available. Sanitation and health will improve the effects of chronic diseases and other impediments to the welfare of families and education and increase productive opportunities (WORLD WATER COUNCIL - FAO, 2015).

Water security and energy, transport, food, land use and the environment. In a changing world (from population growth, economic dynamics, and climate change) we need flexible multipurpose infrastructure (OECD, 2015). 


\section{Electricity}

Electricity can be generated by water from fossil fuels by means of nuclear reactors, using the sun or the wind. In countries where water is abundant, they are built large plants with reservoirs in the form of a large lake for generating electric power. This can be a problem if not have a plan to avoid the lack of water for consumption when you have a drought or problems with flooding when the rainy period.

As the water is intended for agriculture and for human use, the construction of an electricity generation plant should be planned also predicting impacts on the environment because of the need to build large water reservoirs to move the turbines that will generate electricity.

Water, electric energy and food production are directly related and interdependent. The production of energy from water must be carefully managed because it can consume all existing water and not be left for food production and therefore we cannot eradicate hunger in the world (FAO, 2013). Reports indicate that 1.3 billion people lack access to electricity, 780 million people worldwide lack access to safe water and 2.5 billion sanitation services.

\section{HDI - Human Development Index and GDP-Gross Domestic Product}

The Human Development Index (HDI) is a summary measure of long-term progress in three basic dimensions of human development: income, education and health while the gross domestic product (GDP) considers only the economic dimension of development. The Latin American region has HDI better than OTHER regions but it does not have better data that Advance Economies AVECO region where they are countries like Denmark, Germany, Japan.

GDP shows the total of domestically produced goods in one country and the higher the better economic activity to generate employment, income, the greater the supply of goods and services. On the other hand, the increase of GDP requires the use of more production resources. If production resources are employed in increasing the production of goods and services without planning and adoption of renovation policies of the funds, the company may have problems with the shortage or total exhaustion.

Between 1980 and 2000 world GDP significantly increased because of greater trade liberalization and participation of emerging countries. In this period, world GDP grew tenfold while exports have increased more than thirty times and this is due to the fact that countries such imports made by Canada and Japan for products that are produced in China and Mexico, for example and that have low production cost. 
Table 1 Average Growth in\% of GDP in 1980, 1990 and 2000 Selected Regions

\begin{tabular}{c|c|c|c} 
Região & 1980 & 1990 & 2000 \\
\hline World & 3.2 & 2.9 & 4.0 \\
\hline Developed countries & 3.0 & 2.7 & 2.4 \\
\hline Emerging Countries & 3.5 & 3.3 & 6.4 \\
\hline África & 2.6 & 2.3 & 5.6 \\
\hline Central and Eastern Europe & 2.1 & 1.2 & 4.9 \\
\hline Developing Asia & 3.5 & -4.8 & 7.4 \\
\hline Middle East & 6.8 & 7.3 & 8.1 \\
\hline Latin America & 1.4 & 4.4 & 5.4 \\
\hline
\end{tabular}

Source: Parkin, 2009

The GDP growth of the regions shown in Table 1 shows the intensification of international trade in emerging countries, Africa and Middle East. The highlight is the global growth in 1990 to $2.9 \%$ and then $4 \%$ in 2000 . Another important highlight is emerging that goes from $3.3 \%$ in 1990 to $6.4 \%$ in 2000 . The Commonwealth of Independent countries and Mongolia leaves a negative growth in 1990 of $4.8 \%$ and less goes to $7.4 \%$.

As for Latin America countries such as Chile, Venezuela, Colombia, Argentina, Mexico and Brazil the momentum of the trade (exports plus imports) have transformed the structure of the economy with growth of the order of a hundred percent order from 3.3 in 1990 to 6.4 in 2000; at the same time exports of commodities from China, representing the Asian continent, was responsible for this new dynamic of international trade numbers (PARKIN, 2009).

\section{METHODOLOGICAL PROCEDURES}

For the purpose of analyzing how the Iberoamerican Region as a whole is doing regarding Basic Needs the present study compares present related development conditions of three Regions: The Iberoamerican Region (AIBER) with 21 countries, an Advance Economies Region (AVECO) with 27 countries and the rest or other countries (OTHER) with 84 countries. The study begins with an exploratory descriptive data analysis to understand behavior and relationships among indicators related to basic needs such as food, water, electricity, energy using a table with a total of 132 countries for this purpose. Regions were compared using ANOVAs to determine issues( indicators ) that were more relevant to differentiate the selected 3 Regions around the world, based on the Knoema statistical database that allows us having a better vision about the worldwide situation today in particular regarding Basic Needs(CRESWELL, 2103).

\section{ANALYSES AND DISCUSSION OF RESULTS}

\section{Analysis of 132 countries}

After some statistical analysis eight variables were selected as more representative such as Depth of food deficit (calories / undernourished person), Access to piped water (\% Of pop), Rural vs. Urban access to improved water source (absolute difference between (\% of pop.) Access to improved sanitation facilities (\% of pop.) Access to electricity (\% of pop.), Quality of electricity 
supply ( $1=$ low, 7 = high) Renewable internal freshwater resources per capita (cubic meters). Besides these Analytic Variables some Synthetic Indicators were also included in the analysis: SPI - Social Progress Index, HDI - Human Development Index, Governance index, EPI - Environmental Protection Index, HPI - Happy Planet Index, OHI - Ocean Health Index, GINI Index, EV - water resources. Figure 1 shows how these variables are intercorrelated.

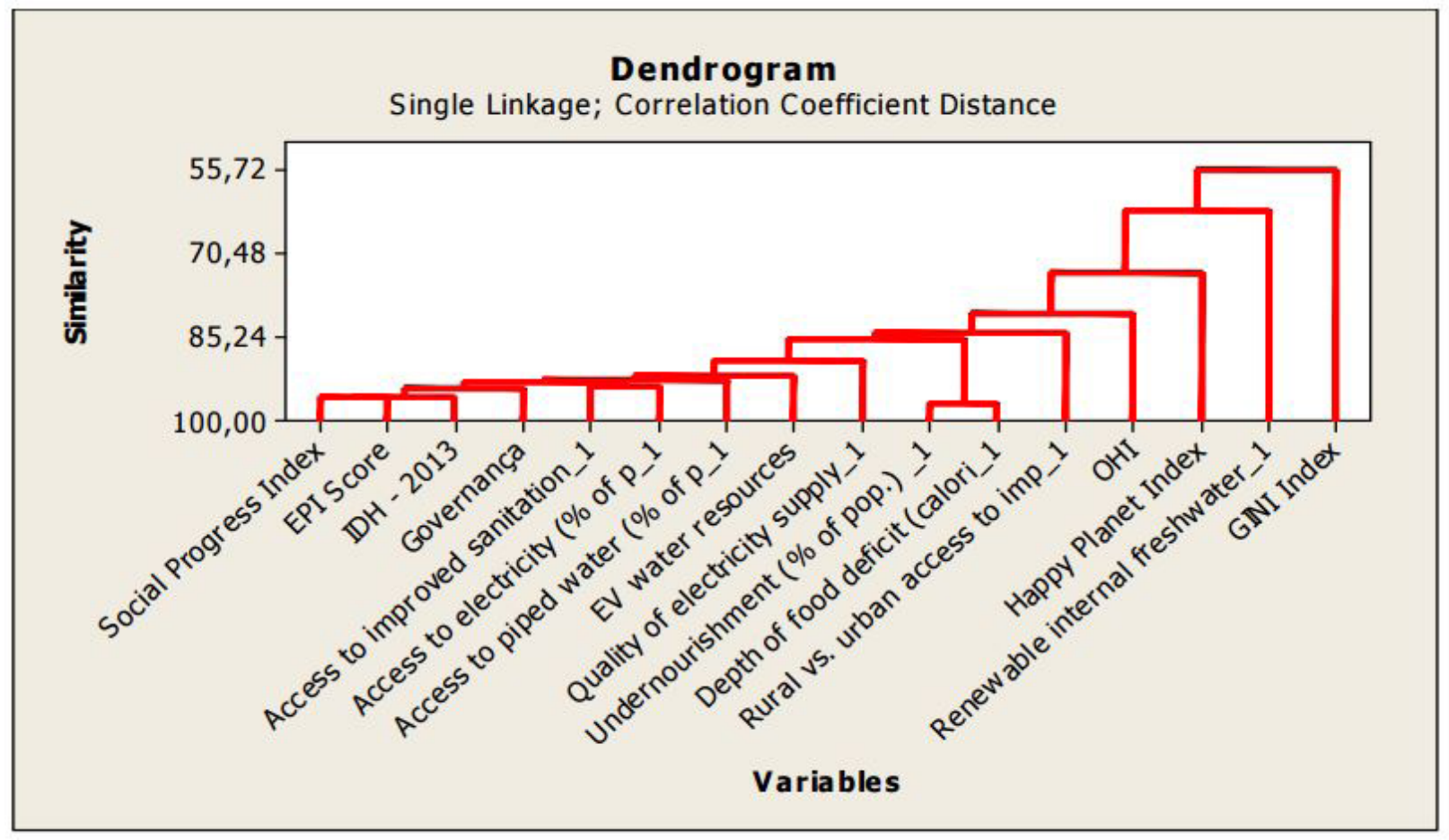

Figure 1 Intercorrelations Among the Variables

This figure 1 show in particular a high degree of behavior similarity among the variables: SPI, EPI, HDI, Governance, Access to improved sanitation, Access to piped water and Access to electricity. Moreover SPI, and HDI are very closely related, so for practical purposed one may simply use this last one that is simpler and have a longer data history, and actually both are basically dealing with Social Conditions

Table 2 ANOVA Comparing Means of the 3 Regions: AIBER, AVECO and OTHERS; As well as Fs for the variables All variable were Normalized (0 - 100), and Positivized ( the higher the better )-

\begin{tabular}{c|c|c|c|c|c|c|c|c} 
3R & HDI & EPI & HPI & OHI & ELECTR & EVWATER & FOOD & GOV \\
\hline AIBER & 65.92 & 52.7 & 72.36 & 61.57 & 92.81 & 20.15 & 79.82 & 42.48 \\
\hline AVECO & 87.36 & 81.39 & 50.58 & 73.15 & 99.73 & 79.35 & 97.88 & 83.25 \\
\hline OTHER & 46.74 & 37.95 & 41.79 & 63.2 & 66.42 & 13.1 & 70.18 & 33.36 \\
\hline F & 43.45 & 69.68 & 22.69 & 29.45 & 15.48 & 119.91 & 15.16 & 97.02
\end{tabular}

Table 2 helps to compare the 3 Regions. The higher the $\mathrm{F}$ the higher the difference among the 3 Regions; so that one can to what extent see that the Synthetic Indicators Governance 
(GOV) and EV Water Resources ( EVWATER ) are the ones that make more difference; this last one in particular due to the fact that AVECO Region has a much higher value $(79,35)$ than the other two Regions. As a matter of fact countries like Denmark, Germany, Japan, and United States differ a lot regarding EVWATER as compared to countries in Africa for example that are part of the OTHERS Region. This could be seen very clearly in Figure 2 that allows more easily to visualize differences and compare the regions observing where and how much do they differ each other in relation to each of these 8 dimensions.

This Figure 2 and Table 3 in particular, show that AIBER is doing even better that AVECO, when we are talking about the Happy Planet Index (HPI). This may be so due to the important fact of large forest areas in the region such as is the case of in the case of Brazil, Costa Rica, Dominican Republic; while other countries in place of forests have large desert areas like the case of North Africa region: Egypt, Morocco, Algeria, Libya, Tunisia, Mauritania, Mali, Sudan and Chad which is the Sahara desert.

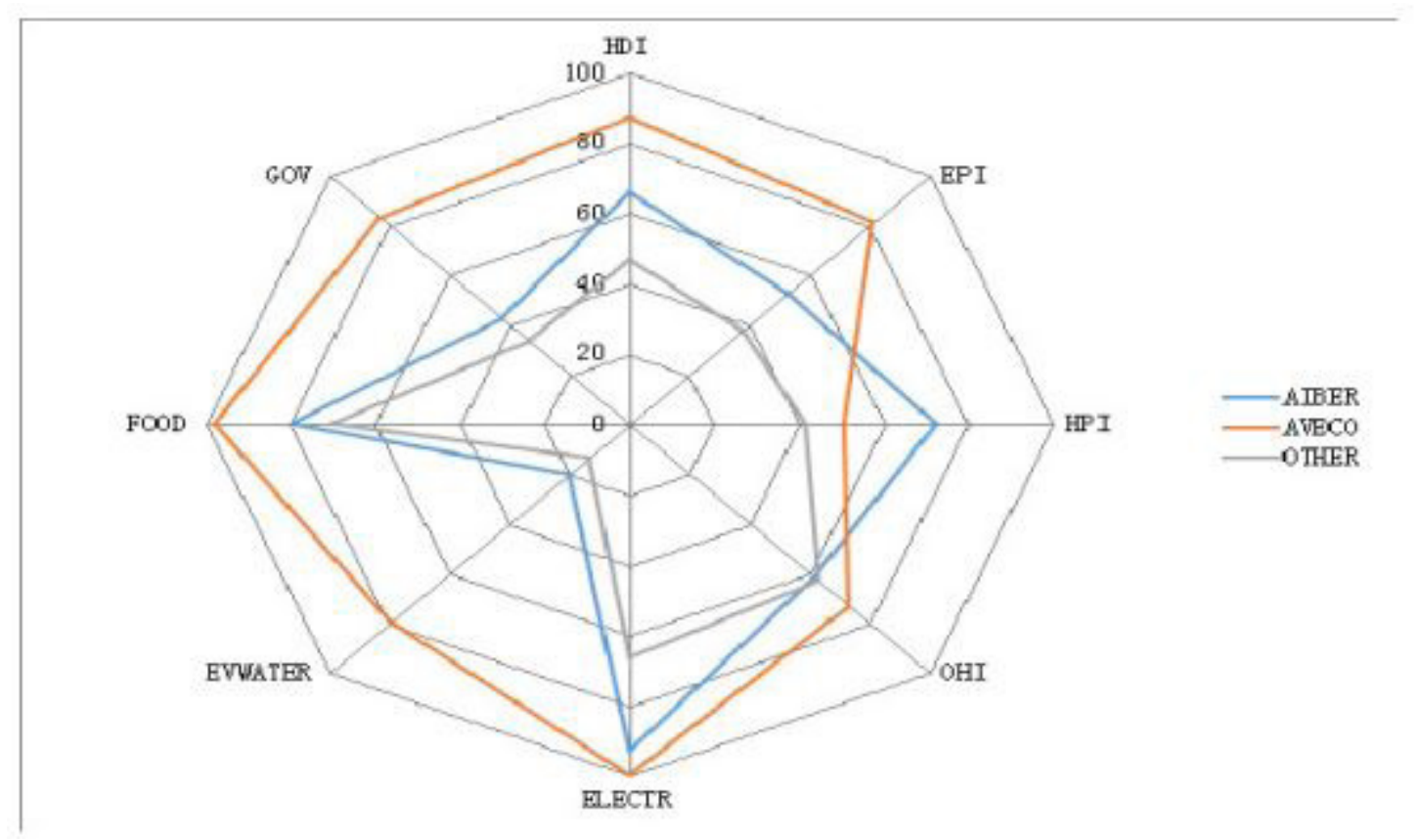

Figure 2 Means of the Regions: AIBER, AVECO e OTHERS

On the other hand no doubt more Advanced Developed Economies (AVECO) shows better conditions regarding: HDI, EPI, Food and Electricity. As matter of fact Access to Electrify shows values for AIBER and AVECO regions much higher than the OTHERS Regions although the $F$ value is small ( 15,48 ) which is due to a large variability of this variable within the Regions itself. This variable seems to indicate shows that there is power supply to the grid of the population but it may not be constant or lack quality of supply. For example, the countryside that exists in much of the OTHERS region that concentrates the countries of South Africa, Tanzania, Togo, Mozambique and Liberia still don't have energy supply for everyone. 
Table 3 ANOVA Comparing the 3 Regions Using the Happy Planet index (HPI)

\begin{tabular}{l|c|c|c|c|c}
\hline \multicolumn{7}{c}{ One-way ANOVA: Happy Planet Index versus REGIAO } \\
\hline Source & DF & SS & MS & F & P \\
\hline REGIAO & 2 & 15846 & 7923 & 22.69 & 0.000 \\
\hline Error & 129 & 45048 & 349 & & \\
\hline Total & 131 & 60894 & & & \\
\hline
\end{tabular}

$\mathrm{S}=18.69 \quad \mathrm{R}-\mathrm{Sq}=26.02 \% \quad \mathrm{R}-\mathrm{Sq}(\mathrm{adj})=24.87 \%$

Individual $\quad 95 \% \quad$ CIs For Mean Based on

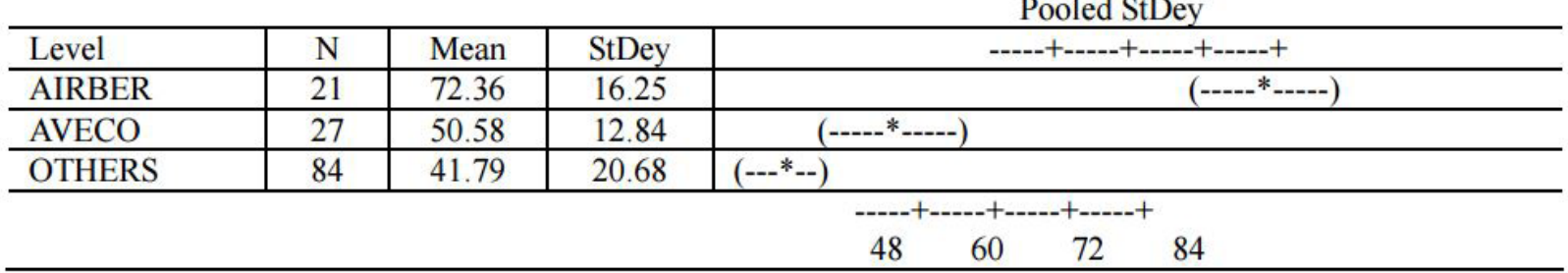

However, and as its shown in Table 4 regarding Care for the environment - EPI Environmental Protection Index, AIBER is nearest the Region Other in the range of values between 45 and 60, while the AVECO region is doing much better distant and very near 90 in the interval between 75 and 90. of the countries in the Latin American Region the individual data shows that El Salvador, Paraguay and Peru with the worst indices close to $36 \%$. In this region are the best: Ecuador, Costa Rica and Chile.

Table 4 ANOVA Comparing the 3 Regions Using the Environmental Protection Index (EPI)

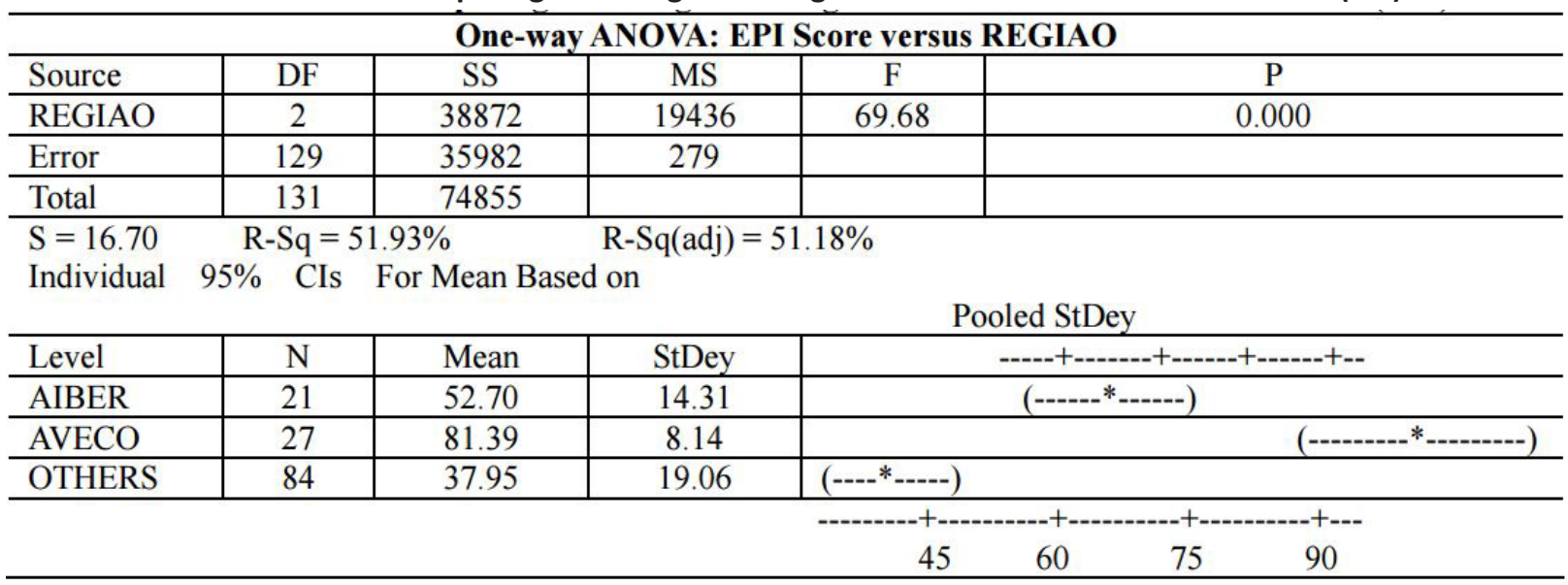

Last, but not least, The Human Development Index HDI, as an essential leading indicator, clearly shows how the population is doing regarding basic social conditions. Table 5 shows that the AIBER is very well in the middle between the worst (OTHERS) and the best region (AVECO). Among the Countries that are doing worst are Pakistan, Yemen, Angola, while among the ones that are best examples we do have Sweden, Switzerland, Norway, New Zealand. All in all AIBER is not doing that bad but we still has a long way to go. 
Table 5 ANOVA Comparing the 3 Regions Using the Human Development Index (HDI)

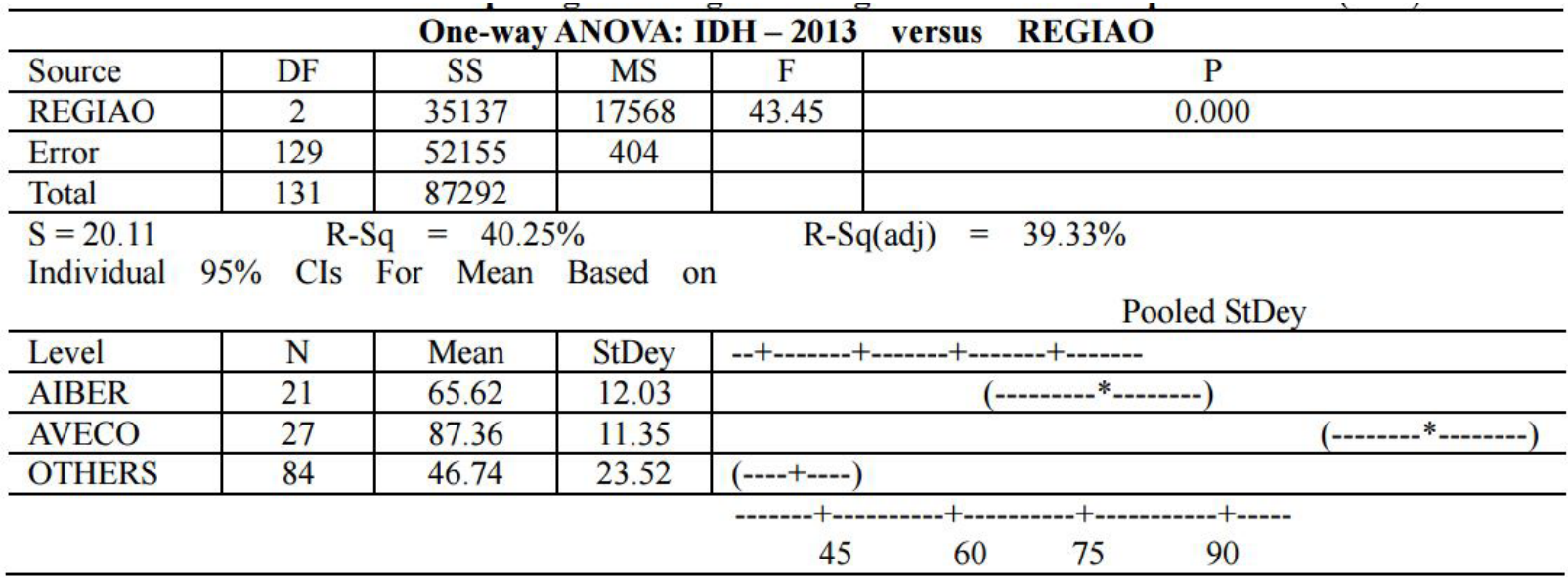

\section{CONCLUSION}

The Base of the Maslow's Hierarchy of Needs Pyramid are the Physiological or Basic Needs, which in fact is very close to the next level related to Security Needs; so if one really wants to help overcoming basic human challenges in developing regions, it's important to start from there and see how are they doing and what and where there is a greater need to improve.

This study of the performance of 132 countries of the 3 Regions - Iberoamerican Region( AIBER ), AVECO Region (more developed countries) and OTHERS Region (less developed countries ) is based on the analysis of indicators related to the Basic Needs of Food, Water, Electricity, Energy.

Basic Needs conditions are closely and systemically interconnected, and reflect development conditions; moreover they may be monitored and analyzed through a set of worldwide country indicators that may help for a Regional Diagnosis as well as for improving Strategic Planning.

For this purpose the indicators used on this paper shows that: a) Even countries with low GDP may still improve food quality through increased investment in food production; $b$ ) Appropriate public policies may lead to increased quality of life with food, water and energy; c) More and more is necessary to increase not only quantity but also quality of products and processes, particularly when thinking more systemically on Sustainable Development. Hence Growth may help to raise incomes and reduce hunger, but higher economic growth may not reach everyone or even if does, there may situations where or when this doesn't necessarily means a higher quality livelihood; moreover it may not lead better work conditions for all, unless policies specifically target social inclusion processes, especially in relation to those still living in rural areas. In poor countries, hunger and poverty reduction will only be achieved with growth that is not only sustained, but also broadly shared. More specifically this paper shows that even though basic needs at the Iberoamerican Region may have being improved along the time, there is still a long way to go and there is an increasing need to be concern, for Local and Global Sustainable Development Reasons, to take care not only of quantity of Basic Needs but also of Quality of Products and Processes, for present and Future Generations. 


\section{BIBLIOGRAPHIC REFERENCES}

[1] Creswell, J. W. Research design: Qualitative, quantitative, and mixed Methods approaches. Sage, 2013

[2] Parkin, M.. Economy. São Paulo: Addison Wesley, 2009

[3] FAO Statistical Yearbook , 2013 https://www.fao.org.br/FAOddma.asp Retrieved 20.7.2015

[4] Towards A Water and Food Secure Future. World Water Council. 2015 http://www.worldwatercouncil.org/

[5] GPS Guide - Sustainable Public Management, NEF PUCSP, Brazil http://www.pucsp.br/posgraduacao/mestrado-e-doutorado/gps-gestao-publica-sustentavel, 2014

[6] Knoema. Database http://pt.knoema.com/atlas/Z\%C3\%A2mbia/\%C3\%8Dndice-deDesenvolvimento-HumanoRetrieved 29.6.2015

[7] Maslow, A. Hierarchy of Needs https://en.wikipedia.org/wiki/Maslow\%27s_hierarchy_of_ needs

[8] UN-WATER. The United Nations Inter-Agency Mechanism On All Related Issues, Including Sanitation.

http://www.unwater.org/

http://www.righttowater.info/rights-in-practice/catarina-de-albuquerque/

[9] Water: fit to finance? Catalyzing national growth through investment in water security., 2015. http://www.unwater.org/worldwaterday

[10] World Water Council Integrated Water Resource Management. 7th World Water Forum, 2015. http://www.worldwatercouncil.org/Retrieved 21.7.2015

[11] World Bank. World Bank Open Data, 2015

http://data.worldbank.org/

http://blogs.worldbank.org/opendata/what-are-trade-blocs-and-how-do-two-latin-america-slargest-compare

http://web.worldbank.org/WBSITE/EXTERNAL/TOPICS/EXTPOVERTY/EXTPA/0,,contentMDK:2239 7595 pagePK:210058 piPK:210062 theSitePK:430367,00.html 